\title{
Cancer Treatments of the Irreversible Electroporation
}

\section{Jin-jun Zhu, Jia-li Bao*, Chao-yang Zhu and Qi-feng Fu}

Research Team of Biophysics and Medical Engineering, School of Medicine, Zhejiang University, Hangzhou, China

\begin{abstract}
Irreversible electroporation (IRE) is a kind of non-thermal tumor treatment strategy. Based on this, Nanoknife emerged, which is approved by FDA in 2011. From then on, clinical application of nanosecond electrical pulsed have showed an explosive growth. At the cell level, the biophysical mechanism of nonthermal irreversible electroporation of electrical pulsed was studied. At the animal level, it has studied the safety of irreversible electroporation and preclinical animal experiments, also the clinical application of irreversible electroporation. We reviewed Animal studies of IRE and Clinical application of IRE. Also traditional medical imaging methods such as CT, magnetic resonance imaging (MRI) and ultra-sound imaging can be used in the IRE therapy. The evidences can prove the beneficial effects and safety of IRE in tumor treatment and verify the potential of IRE in clinical treatment to some extent. However, larger clinical trials are still needed to confirm these conclusions. Hopefully, as we go deeper into IRE, we get a more thorough understanding of it and the application will appear in various fields.
\end{abstract}

Publication History:

\section{Introduction}

Nanosecond pulse electric field refers to a kind of pulse electric field whose pulse width is at the nanosecond level, this kind of electric field can produce reversible electroporation [1] and irreversible electroporation (IRE) [2] on the cell membrane. Reversible electroporation is a transient hydrophilic hole in the cell membrane induced by the pulsed electric field [3]. This phenomenon was first discovered by Neumann and Rosenheck that electrical impulses caused changes in the permeability of the membrane [4]. Then Zim-mermann et al. found that $1-10 \mathrm{kv} / \mathrm{m}$ pulse electric field can break through the red cell membrane, form a dielectric breakdown of the cell membrane, releasing hemoglobin, and the hemolytic mechanism causes cellular mechanical rupture or thermal rupture. At $37^{\circ} \mathrm{C}$ ruptured cells closed again [5]. This phenomenon is called electroporation of the cell membrane.

However, Sale et al. found that under high voltage pulsed electric field, red blood cells and protoplast produce lysis and cell death [6]. Sun caixin et al. believed that with the increase of the pulsed electric field dose, the irreversible rupture of cell membrane caused cell death, which was called irreversible electric breakdown. It was observed that SKOV3 cells of human ovarian adenocarcinoma presented retained shape and complete cell membrane, but the mitochondrial swelling and cavitation showed the phenomenon of cell death caused by highvoltage pulsed electric field [7].

Since the FDA approved the Nanoknife in 2011, the IRE clinical application of nanosecond pulsed electric field showed an explosive growth. At the cell level, the biophysical mechanism of non-thermal irreversible electroporation of pulsed electric field was studied. At the animal level, we studied the 1 safety of irreversible electroporation and preclinical animal experiments, also the clinical application of irreversible electroporation.

\section{Animal Studies of Irreversible Electroporation}

Before the application of irreversible electroporation in clinic, the basis of animal experiment should be provided. These experiments can prove the beneficial effects and safety of IRE in tumor treatment and verify the potential of IRE in clinical treatment to some extent. This article summarize part of them.

\section{The rabbit}

In the experiment that irreversible electroporation could eradicate VX2 hepatic tumors in rabbits, IRE electrodes advanced toward the implanted tumor center from the three overlapping directions of lower, middle and lateral, covering all the implanted VX2 tumors to treat the entire tumor [8].

\section{The canine}

The first case of irreversible electroporation for intracranial canine proved that it is safe to use irreversible electroporation in canine intracranial surgery [9]. The safety of NTIRE in the brain was examined with specially designed dogs, and NTIRE was applied to the first step of local ablation treatment for brain cancer and other intracranial diseases [10]. Garcia et al. proved that the treatment of Malignant Glioma com-bined with NTIRE is rapid and minimally invasive, and effective in ablating pathologic heterogeneity brain tumor tissue without aggravating cerebral hemorrhage [11].

\section{The swine}

IRE treatment of pig pancreatic tissue is safe and effective. TTC staining predicted the resection of the pancreas within 2 hours after treatment. Further studies are needed to determine the optimal electrode spacing and voltage for IRE ablation in the pancreas. Further studies are needed to determine the role of IRE in pancreatic tumor ablation [12].

In the treatment of complete thickness ablation of normal pig bile duct, it is proved to be feasible and safe. Moreover, the thermal mechanism of RFA and laser ablation may cause the risk of deep tissue infiltration and perforation and cholangitis. IRE, by contrast, helps to

*Corresponding Author: Dr. Jia-li Bao, Research Team of Biophysics and Medical Engineering, School of Medicine, Zhejiang University, Hangzhou, China; E-mail: baojl@zju.edu.cn

Citation: Zhu J, Bao J*, Zhu C, Fu Q (2018) Cancer Treatments of the Irreversible Electroporation. Int J Clin Res Trials 3: 12. doi: https://doi.org/10.15344/2456$8007 / 2018 / 129$

Copyright: (c) 2018 Zhu et al. This is an open-access article distributed under the terms of the Creative Commons Attribution License, which permits unrestricted use, distribution, and reproduction in any medium, provided the original author and source are credited. 
insulate the extracellular matrix from the effects of ablation, reducing the risk of biliary penetration ablation, and reducing the incidence of adverse events [13].

The ablation of the colon [14], lymphaden [15], pancreatic tissue [16-18], gastric wall [19], epidural space of spine [20], liver [21], ureter [22], vertebrae [23] of the pig demonstrate the feasibility and security of IRE.

\section{The rat}

Guo et al. demonstrated the efficacy of IRE in targeted treatment of liver tumors in a transplanted mouse liver cancer model for the first time [24]. In the mouse experiments, IRE as a treatment for nonmetastatic pancreatic tumors showed significant anti-tumor effects and prolonged survival in mice [25]. It was found that irreversible electroporation could prolong the overall survival time of liver tumor mice and reduce the growth rate of tumor [26]. Synergistic effects between Moderate Heating and IRE have been demonstrated in in vitro tumor ablation and in vivo tumor reduction. Controllable and moderate heating can improve the efficacy of irreversible electroporation in the treatment of pancreatic cancer, and significantly expand the ablation area of tumor in vitro and reduce tumor growth in vivo [27]

\section{Clinical Application of Irreversible Electroporation}

Human clinical studies have begun after encouraging results in animal models.

\section{Pancreatic cancer}

Pancreatic cancer is one of the world's deadliest cancers, with a fiveyear survival rate as low as 6 percent. Most pancreatic cancer patients develop locally advanced or metastatic disease at diagnosis [28].

IRE ablation for locally advanced pancreatic cancer is safe and feasible and can be used as a major local treatment [29]. This metaanalysis suggested that IRE use may be safe and effective for prolonged survival in pancreatic cancer patients [30]. In the experiments conducted by Martin et al., 200 patients were followed at a median of 29 months, and the overall survival rate was observed at 19.25 months from the time of treatment [31].
Patients who had concurrent IRE therapy had greater local remission and improved overall survival compared to those who had only radiation and chemotherapy [32]. The recurrence rate was lower (3\%) after a median follow-up of 29 months, suggesting that even in advanced patients, treatment with IRE after chemotherapy can inhibit tumor regeneration and significantly improve the quality of life [33]. Irreversible electroporation combined with allogeneic natural killer cell immunotherapy can significantly improve the median PFS and OS in stage iii pancreatic cancer and extend the median OS in stage IV pancreatic cancer. Multi-allogeneic natural killer cell infusion is associated with better prognosis of stage III pancreatic cancer [34].

Ansari et al. summarized a total of 446 patients in 10 studies. Percutaneous drainage was performed in 142 patients and in 304 patients [35]. Tumor size are between 2.8 and 4.5 centimeters. Postoperative complications occurred in $35 \%$ of patients, most of them less severe. Nine patients $(2.0 \%)$ died after surgery. The technical success rate is $85-100 \%$. The mean survival time of free recurrence after treatment of IRE was 2.7 to 12.4 months. The median postoperative overall survival was 7-23 months. Total survival was highest when IRE was combined with pancreatectomy.

The information of IRE therapy to pancreatic cancer is listed in Table 1.

\section{Liver cancer}

Irreversible electroporation (IRE) is a new type of percutaneous ablation technology developed in the last decade, whose application in the treatment of primary and metastatic liver diseases is progressing rapidly [47].

Hepatocellular carcinoma (HCC) remains a major health concern at present because of its increasing incidence and the complexity of its treatment [48]. It has risen to become the third leading cause of cancer related deaths in the world, killing more than 800,000 people a year [49]. Studies have shown that IRE therapy for non-resected liver cancer is a viable, safe and effective treatment, and will not cause serious complications even if the excised lesions are close to the main branches of the portal vein. The diagnostic accuracy of MRI, CT, and CEUS for IRE treatment in HCC patients was similar during the 1, 3, and 6 months of follow-up to assess the ablative region [50].

\begin{tabular}{|l|l|l|l|l|l|l|l|}
\hline Author & $\begin{array}{l}\text { Pulse Inten-sity } \\
(\mathrm{V} / \mathrm{cm})\end{array}$ & Pulse duration & pulses number & $\begin{array}{l}\text { electrode gap } \\
(\mathrm{cm})\end{array}$ & $\begin{array}{l}\text { Exposure } \\
(\mathrm{cm})\end{array}$ & electrodes & $\begin{array}{l}\text { Tumor size } \\
(\mathrm{cm})\end{array}$ \\
\hline R.CG Martin 2012 [29] & 1,500 & $100 \mathrm{~ms}$ & & & 1.5 & 4 & 3 \\
\hline Kai-Wen Huang, 2018 [36] & 1500 & $90 \mu \mathrm{s}$ & 90 & $1.8-2.5 \mathrm{~cm}$ & $1.0-1.5$ & $3-6$ & $3.3(2.5-7)$ \\
\hline M. F. Rashid, 2018 [37] & $1400-2000$ & $90 \mu \mathrm{s}$ & 270 & $1.5-2$ & $0.5-1.5$ & & $<4.0$ \\
\hline M. Papoulas, 2018 [38] & 1500 & $70-90 \mathrm{us}$ & 90 & $1.5 \mathrm{~cm}$ & $2-2.5$ & & \\
\hline L.G. P. H. Vroomen 2017 [39] & 1500 & $90 \mu \mathrm{s}$ & 100 & $15-24 \mathrm{~mm}$ & 1.5 & $3-6$ & $\leq 5$ \\
\hline P. Marsanic 2017 [40] & 1500 & $100 \mathrm{~s}$ & & $2-\mathrm{cm}$ & 1.5 & & 4 \\
\hline J. A. Vogel, 2017 [41] & 1500 & $90 \mu \mathrm{s}$ & 90 & $2.5 \mathrm{~cm}$, & 1.5 & Three to six & $\leq 5$ \\
\hline S. Orcutt 2017 [42] & 1050 to 2100 & $90 \mu \mathrm{s}$ & 80 & 0.7 to $1.4 \mathrm{~cm}$ & 1.5 & 3 & \\
\hline Y. Ekici 2016 [43] & 1500 & $100 \mathrm{~s}$ & & $2 \mathrm{~cm}$ & 1.5 & 3 & \\
\hline L.Yan 2016 [44] & 1500 & $90 \mu \mathrm{s}$ & 100 & 2 & $1.0-1.5$ & & $4.2(\mathrm{median})$ \\
\hline S. Paiella 2015 [45] & 1500 & $70 \mathrm{~ms}$ & 90 & $1-2$ & & 6 & $<4$ \\
\hline M. J. Weiss 2014 [46] & 1500 & $70-90 \mathrm{~ms}$ & 90 & $0.5-2.0 \mathrm{~cm}$ & 1.5 & & $<3.5$ \\
\hline
\end{tabular}

Table 1: IRE therapy to pancreatic cancer. 
The use of IRE should be included in a multidisciplinary discussion of the treatment of primary and secondary hepatic metastases around blood vessels. In addition, IRE therapy can give unresectable patients the opportunity to have a resection or a two-stage hepatectomy [51].

Kingham et al. investigated the safety of IRE in the treatment of hepatic malignant tumors by hepatic veins and portal veins [52]. CHEUNG et al. determined the therapeutic safety of liver malignancies near the central site of the main biliary tract [53]. An irreversible electrical perforation (IRE) was successfully treated for a 65-year-old man with hepatocellular carcinoma [54]. The safety of IRE indicates that the integrity of the central structures such as the bile duct, hepatic artery, and portal vein can be protected after the IRE treatment [55].

The information of IRE therapy to liver cancer is listed in Table 2.

\section{Prostatic cancer}

Irreversible electroporation has been used in clinical practice for many years as a non-thermal therapy for prostate cancer [61]. Data support IRE as a viable treatment for all prostate segments, with no significant differences in quality of life effects [62]. Irreversible electroporation is effective for the ablation of prostate tumors, since most men do not find any signs of residual cancer when they are biopsied six months after the ablation [63]. Irreversible electroporation ablation is mainly manifested as fibrosis, necrosis and epithelial detachment of glandular structure. The ablation zone is well demarcated, showing a clear line between viable and non-viable tissue [64].

Formally, there is no fundamental difference between IRE's risk and the procedures established to date to treat localized prostate cancer [65]. Irreversible electroporation (IRE) treatment for local prostate cancer (PCA) is still considered experimental, although initial results confirm its high developmental potential as a local treatment for organ and functional protection [66]. Van den Bos et al. described ablation sites as two to three times larger than expected and spread from the prostate capsule to the neurovascular bundle, which carries the associated risk of stress incontinence and erectile dysfunction [67].

The information of IRE therapy to prostatic can-cer is listed in Table 3.

\section{Breast cancer}

Currently, the clinical treatment of breast cancer usually includes the combined treatment of surgical excision or mastectomy, radiotherapy and adjuvant chemotherapy [71]. One study suggested that IRE could be a favorable option for surgical resection of the breast reserved treatment [72]. Rapid lesion clearance will allow healthy cells to repopulate the initially affected areas and treatment margin [73].

The electric field applied to the thymic matrix lymphopoietin (TSLP) signal can be affected when IRE uses short-time transient voltage, and the molecule has known pro-tumor effects through immune-cell phenotype regulation [74].

\section{Irreversible Electroporation and Imaging}

Similar to radiotherapy treatment, traditional medical imaging methods such as CT, magnetic resonance imaging (MRI) and ultrasound imaging can be used in preoperative and intraoperative treatment plans to determine effective tissue volume ablation [74].

Different organizations should apply different imaging methods according to the actual situation. Such as: The anatomical structure of hepatic portal is complex, and the distance between hepatic duct,

\begin{tabular}{|c|c|c|c|c|c|c|c|}
\hline Author & $\begin{array}{l}\text { Pulse Inten- } \\
\text { sity }(\mathrm{V} / \mathrm{cm})\end{array}$ & $\begin{array}{l}\text { Pulse } \\
\text { duration }\end{array}$ & $\begin{array}{l}\text { pulses } \\
\text { number }\end{array}$ & $\begin{array}{l}\text { electrode } \\
\text { gap }(\mathrm{cm})\end{array}$ & $\begin{array}{l}\text { Ex-posure } \\
(\mathrm{cm})\end{array}$ & electrodes & $\begin{array}{l}\text { Tumor size } \\
(\mathrm{cm})\end{array}$ \\
\hline \multirow[t]{5}{*}{ Robert J S Coelen, 2017 [56] } & 1500 & $90 \mathrm{~ms}$ & 90 & $1.0-2.4$ & $2.0 \mathrm{~cm}$ & 2 & $3.0 \times 2.5 \times 1.0$ \\
\hline & & & & & & 3 & $3.0 \times 2.5 \times 2.05$ \\
\hline & & & & & & 4 & $3.0 \times 2.5 \times 2.5$ \\
\hline & & & & & & 5 & $3.0 \times 4.0 \times 3.0$ \\
\hline & & & & & & 6 & $3.0 \times 4.7 \times 3.2$ \\
\hline S. E. Herwald, 2016[57] & $1,800-2,200$ & & 90 & $1.5-2.0$ & 2 & & 2.4 \\
\hline Eller 2015[58] & 1,500 & $100 \mu \mathrm{s}$ & 90 & 2 & 2 & $2-4$ & \\
\hline R. G. Cheng 2015[55] & 1,500 & $90-100 \mu \mathrm{s}$ & 90 & 1.5 & $1.5-2.0$ & & $\leq 3 \mathrm{~cm}$ \\
\hline R. CG. Martin,2015[59] & 1,500 & $70-90 \mathrm{~ms}$ & 90 & & & & \\
\hline B. Kos 2015 [60] & $1,500-1,700$ & $90 \mu \mathrm{s}$ & 90 & 2.2 & 2 & & $18.05 \mathrm{~cm}^{3}$ \\
\hline
\end{tabular}

Table 2: IRE therapy to liver cancer.

\begin{tabular}{|c|c|c|c|c|c|c|}
\hline Author & $\begin{array}{l}\text { Pulse Intensity } \\
(\mathrm{V} / \mathrm{cm})\end{array}$ & Pulse dura-tion & pulses number & $\begin{array}{l}\text { electrode } \\
\text { gap }(\mathrm{cm})\end{array}$ & Exposure $(\mathrm{cm})$ & electrodes \\
\hline M. J. Scheltema, 2018 [68] & $1,600 \mathrm{~V}-2,550 \mathrm{~V}$ & $70 \mu \mathrm{s}$ & 80 & $0.6-2.2$ & $1.5-2.0$ & \\
\hline W. van den Bos, 2016 [64] & $1,200-2,100$ & $90 \mu \mathrm{sec}$ & 90 & $1.0-2.0$ & $1.5 \mathrm{~cm}$ & \\
\hline W. van den Bos, 2018 [69] & 1,500 & $790 \mu \mathrm{s}$ & 90 & $5-\mathrm{mm}$ & & \\
\hline S. L. Dong, 2018 [61] & 1500 & $100 \mathrm{~ms}$ & 250 & $<2 \mathrm{~cm}$ & $1.0-3.0$ & $2-6$ \\
\hline M. J. V. Scheltema1, 2016 [70] & 1500 & $100 \mu \mathrm{s}$ & 90 & & & \\
\hline
\end{tabular}


portal vein and hepatic artery is close. Hemorrhagic fever with renal syndrome may be associated with serious complications. In one study, percutaneous electrode placement will be guided by CT fluoroscopy through catheter arteriography to prevent major vascular puncture or electrode placement too close to an important structure [56].

The position of the electrode can be shown on the ultrasound image. The distance between a single pair of electrodes was measure. Based on these measurements, the software installed on the IRE device can calculate the voltage required to produce the ablative electric field. The changes of perfusion in the ablation zone after IRE injection were observed by contrast-enhanced ultrasonography. The technique allows for the localization of electrodes around all patients under image guidance. Target lesions and safe boundaries were within the estimated range of ablation. MRI-TRUS guidance combines the advantages of good visualization of the target lesions by MRI with ultrasound's ability to obtain imaging in real time via mobile devices [75].

\section{Future and Challenges}

In one study of IRE ablation, all tumors were smaller than 3.5 centimeters, except for one tumor whose maximum diameter was greater than 3.5 centimeters [76]. However, if the tumors with a diameter of $3-4 \mathrm{~cm}$ are ablated by IRE, the complete ablation rate will be reduced and the possibility of recurrence will be increased [77].

Numerical and experimental results show that the heterogeneity of liver tissue affects the uniformity of the distribution in the midfield during the treatment of IRE, leading to uneven cell death [78]. The electric field intensity increased in the area around the vessels in the plane perpendicular to the electrode, but decreased significantly in the tissue around the vessels in the parallel plane.

The use of IRE in the liver is limited in tumors which are larger than $3 \mathrm{~cm}$ and limited in operative time. These two factors, along with cost, have prevented IRE from becoming the only certain pattern for all liver tumor ablation. As this technique continues to develop, IRE therapy will increasingly become an ablative treatment for most liver cancers [47].

IRE is not only a promising surgical tissue ablation technique, but also a gene therapy technique. Since IRE ablation may leave intact tumor antigens, these findings have promoted clinical studies of tumor ablation, using immune-stimulating plasmids for the combination of local eradication and systemic immunotherapy [79]. The application of IRE-isogene NK immunotherapy is a new and promising combination therapy [80]. However, larger clinical trials are still needed to confirm these conclusions.

IRE will cause muscle contractions, and H-FIRE seems to be an effective technique to mitigate muscle contractions associated with traditional IRE pulses [81].

Given that the rate of progress has become a viable ablative technique for treating liver malignancies, electroporation may be the preferred ablative treatment for most patients over the next five years. As people's understanding of potential applications from IRE gets wider and wider, and technological advances become more widespread, applications become more common.

\section{Funding}

The project supported by National S\&T Major Project of China (2018ZX10301201-002).

\section{Competing Interests}

The authors declare that they have no competing interests.

\section{References}

1. Weaver JC, Chizmadzhev YA (1996) Theory of electroporation: A review. Bioelectrochemistry and Bioenergetics 41: 135-160.

2. Jiang CL, Davalos RV, Bischof JC (2015) A Review of Basic to Clinical Studies of Irreversible Electroporation Therapy. IEEE Trans Biomed Eng 62: 4-20.

3. Weaver JC, Harrison GI, Bliss JG, Mourant JR, Powell KT, et al. (1988) Electroporation: high frequency of occurrence of a transient highpermeability state in erythrocytes and intact yeast. FEBS Lett 229: 30-34.

4. Neumann E, Rosenheck K (1972) Permeability changes induced by electric impulses in vesicular membranes. J Membr Biol 10: 279-290.

5. Zimmermann U, Pilwat G, Riemann F (1975) Preparation of erythrocyte ghosts by dielectric breakdown of the cell membrane. Biochim Biophys Acta 375: 209-219.

6. Sale AJ, Hamilton WA (1968) Effects of high electric fields on microorganisms. 3. Lysis of erythrocytes and protoplasts. Biochim Biophys Acta 163: $37-43$

7. SUN Cai-xin, YAO Chen-guo, XIONG Lan (2002) Killing effects of pulsed electric fields on malignant tumor cell. Acta Biophysica Sinica 18: 474-477.

8. Lee EW, Wong D, Tafti BA, Prieto V, Totonchy M, et al. (2012) Irreversible electroporation in eradication of rabbit VX2 liver tumor. J Vasc Interv Radiol 23: 833-840.

9. Garcia PA, Rossmeisl JH, Robertson J, Ellis TL, Davalos RV, et al. (2009) Pilot study of irreversible electroporation for intracranial surgery. Conf Proc IEEE Eng Med Biol Soc 2009: 6513-6516.

10. Ellis TL, Garcia PA, Rossmeisl JH, Henao-Guerrero N, Robertson J, et al. (2011) Nonthermal irreversible electroporation for intracranial surgical applications. Laboratory investigation. J Neurosurg 114: 681-688.

11. Garcia PA, Pancotto T, Rossmeisl JH, Henao-Guerrero N, Gustafson NR, et al. (2011) Non-thermal irreversible electroporation (N-TIRE) and adjuvant fractionated radiotherapeutic multimodal therapy for intracranial malignant glioma in a canine patient. Technol Cancer Res Treat 10: 73-83.

12. Charpentier KP, Wolf F, Noble L, Winn B, Resnick M, et al. (2010) Irreversible electroporation of the pancreas in swine: a pilot study. HPB 12: 348-351.

13. Ueshima E, Schattner M, Mendelsohn R, Gerdes H, Monette S, et al. (2018) Transmural ablation of the normal porcine common bile duct with catheterdirected irreversible electroporation is feasible and does not affect duct patency. Gastrointest Endosc 87: 300 e1-300 e6.

14. Luo X, Liang X, Li J, Shi J, Zhang W, et al. (2016) The Effects of Irreversible Electroporation on the Colon in a Porcine Model. PLoS One 11: e0167275.

15. Fritz $\mathrm{S}$, Sommer CM, Longerich $\mathrm{T}$, Kuhn-Neureuther $\mathrm{C}$, Radeleff $\mathrm{B}$, et al. (2017) Successful ablation of lymph nodes using irreversible electroporation (IRE) in a porcine survival model. Langenbeck Arch Surg 402: 465-473.

16. Rombouts SJ, Nijkamp MW, Van Dijck WP, Brosens LA, Konings $M$, et al. (2017) Irreversible Electroporation of the Pancreas Using Parallel Plate Electrodes in a Porcine Model: A Feasibility Study. PLoS One 12: e0169396.

17. Rombouts SJE, Van Dijck WPM, Nijkamp MW, Derksen TC, Brosens LaA, et al. (2017) Clinical and pathological outcomes after irreversible electroporation of the pancreas using two parallel plate electrodes: a porcine model. HPB 19: 1058-1065.

18. Fritz S, Sommer CM, Vollherbst D, Wachter MF, Longerich T, et al. (2015) Irreversible Electroporation of the Pancreas Is Feasible and Safe in a Porcine Survival Model. Pancreas 44: 791-798.

19. Li J, Zeng J, Chen J, Shi J, Luo X, et al. (2017) Evaluation of the safety of irreversible electroporation on the stomach wall using a pig model. Exp Ther Med 14: 696-702. 
20. Tam AL, Figueira TA, Gagea M, Ensor JE, Dixon K, et al. (2016) Irreversible Electroporation in the Epidural Space of the Porcine Spine: Effects on Adjacent Structures. Radiology 281: 763-771.

21. Chung DJ, Sung K, Osuagwu FC, Wu HH, Lassman C, et al. (2016) Contrast Enhancement Patterns after Irreversible Electroporation: Experimental Study of CT Perfusion Correlated to Histopathology in Normal Porcine Liver. J Vasc Interv Radiol 27: 104-111.

22. Srimathveeravalli G, Silk M, Wimmer T, Monette S, Kimm S, et al. (2015) Feasibility of Catheter-Directed Intraluminal Irreversible Electroporation of Porcine Ureter and Acute Outcomes in Response to Increasing Energy Delivery. J Vasc Interv Radiol 26: 1059-1066.

23. Tam AL, Abdelsalam ME, Gagea M, Ensor JE, Moussa M, et al. (2014) Irreversible Electroporation of the Lumbar Vertebrae in a Porcine Model: Is There Clinical-Pathologic Evidence of Neural Toxicity? Radiology 272: 709719.

24. Guo $Y$, Zhang $Y$, Klein R, Nijm GM, Sahakian AV, et al. (2010) Irreversible electroporation therapy in the liver: longitudinal efficacy studies in a rat model of hepatocellular carcinoma. Cancer Res 70: 1555-1563.

25. Jose A, Sobrevals L, Ivorra A, Fillat C (2012) Irreversible electroporation shows efficacy against pancreatic carcinoma without systemic toxicity in mouse models. Cancer Lett 317: 16-23.

26. Sanchez-Velazquez $P$, Castellvi $Q$, Villanueva $A$, Iglesias $M$, Quesada $R$, et al. (2017) Long-term effectiveness of irreversible electroporation in a murine model of colorectal liver metastasis. Sci Rep 7: 44821.

27. Edelblute CM, Hornef J, Burcus NI, Norman T, Beebe SJ, et al. (2017) Controllable Moderate Heating Enhances the Therapeutic Efficacy of Irreversible Electroporation for Pancreatic Cancer. Sci Rep 7: 11767.

28. Tartaglia E, Fabozzi M, Rizzuto A, Settembre A, Abete R, et al. (2018) Irreversible electroporation for locally advanced pancreatic cancer through a minimally invasive surgery supported by laparoscopic ultrasound. Int Surg Case Rep 42: 290-294.

29. Martin RC, Mcfarland K, Ellis S, Velanovich V (2012) Irreversible electroporation therapy in the management of locally advanced pancreatic adenocarcinoma. J Am Coll Surg 215: 361-369.

30. Tian G, Liu X, Zhao Q, Xu D, Jiang T, et al. (2018) Irreversible Electroporation in Patients with Pancreatic Cancer: How Important Is the New Weapon? Biomed Res Int 2018: 5193067.

31. Martin RCG, Kwon D, Chalikonda S, Sellers M, Kotz E, et al. (2015) Treatment of 200 Locally Advanced (Stage III) Pancreatic Adenocarcinoma Patients With Irreversible Electroporation Safety and Efficacy. Ann Surg 262: 486494

32. Martin RC, Mcfarland K, Ellis S, Velanovich V (2013) Irreversible electroporation in locally advanced pancreatic cancer: potential improved overall survival. Ann Surg Oncol 3: 443-449.

33. Belfiore G, Belfiore MP, Reginelli A, Capasso R, Romano F, et al. (2017) Concurrent chemotherapy alone versus irreversible electroporation followed by chemotherapy on survival in patients with locally advanced pancreatic cancer. Med Oncol 34: ARTN 3810.1007/s12032-017-0887-4.

34. Lin $M$, Alnaggar $M$, Liang $S$, Wang $X$, Liang $Y$, et al. (2017) An important discovery on combination of irreversible electroporation and allogeneic natural killer cell immunotherapy for unresectable pancreatic cancer. Oncotarget 8: 101795-101807.

35. Ansari D, Kristoffersson S, Andersson R, Bergenfeldt M (2017) The role of irreversible electroporation (IRE) for locally advanced pancreatic cancer: a systematic review of safety and efficacy. Scand J Gastroentero 52: 11651171.

36. Huang KW, Yang PC, Pua U, Kim MD, Li SP, et al. (2018) The efficacy of combination of induction chemotherapy and irreversible electroporation ablation for patients with locally advanced pancreatic adenocarcinoma. Surg Oncol 118: 31-36

37. Rashid MF, Hecht EM, Steinman JA, Kluger MD (2018) Irreversible electroporation of pancreatic adenocarcinoma: a primer for the radiologist. Abdom Radiol 43: 457-466.

38. Papoulas M, Abdul-Hamid S, Peddu P, Cotoi C, Heaton N, et al. (2018) Irreversible electroporation in borderline resectable pancreatic adenocarcinoma for margin accentuation. J Surg Case Rep 2018: 127.

39. Vroomen L, Scheffer HJ, Melenhorst M, De Jong MC, Van Den Bergh JE, et al. (2017) MR and CT imaging characteristics and ablation zone volumetry of locally advanced pancreatic cancer treated with irreversible electroporation. Eur Radiol 27: 2521-2531.
40. Marsanic P, Mellano A, Sottile A, De Simone M (2017) Irreversible electroporation as treatment of locally advanced and as margin accentuation in borderline resectable pancreatic adenocarcinoma. Med Biol Eng Comput 55: 1123-1127.

41. Vogel JA, Rombouts SJ, De Rooij T, Van Delden OM, Dijkgraaf MG, et al. (2017) Induction Chemotherapy Followed by Resection or Irreversible Electroporation in Locally Advanced Pancreatic Cancer (IMPALA): A Prospective Cohort Study. Ann Surg Oncol 24: 2734-2743.

42. Orcutt S, Kis B, Malafa M (2017) Case report: Irreversible electroporation for locally advanced pancreatic cancer. Int I Surg Case Rep 40: 54-57.

43. Ekici Y, Tezcaner T, Aydin HO, Boyvat F, Moray G, et al. (2016) Arterial complication of irreversible electroporation procedure for locally advanced pancreatic cancer. World J Gastrointest Oncol 8: 751-756.

44. Yan L, Chen YL, Su M, Liu T, Xu K, et al. (2016) A Single-institution Experience with Open Irreversible Electroporation for Locally Advanced Pancreatic Carcinoma. Chinese Med J 129: 2920-2925.

45. Paiella S, Butturini G, Frigerio I, Salvia R, Armatura G, et al. (2015) Safety and Feasibility of Irreversible Electroporation (IRE) in Patients with Locally Advanced Pancreatic Cancer: Results of a Prospective Study. Digest Surg 32: 90-97.

46. Weiss MJ, Wolfgang CL (2014) Irreversible electroporation: a novel therapy for stage III pancreatic cancer. Adv Surg 48: 253-258.

47. Cohen EI, Field D, Lynskey GE, Kim AY (2018) Technology of irreversible electroporation and review of its clinical data on liver cancers. Expert Rev Med Devic 15: 99-106.

48. Donadon M, Solbiati L, Dawson L, Barry A, Sapisochin G, et al. (2016) Hepatocellular Carcinoma: The Role of Interventional Oncology. Liver Cancer 6: 34-43.

49. Li D, Kang J, Golas BJ, Yeung VW, Madoff DC, et al. (2014) Minimally invasive local therapies for liver cancer. Cancer Biol Med 11: 217-236.

50. Granata V, Di Castelguidone ED, Fusco R, Catalano O, Piccirillo M, et al. (2016) Irreversible electroporation of hepatocellular carcinoma: preliminary report on the diagnostic accuracy of magnetic resonance, computer tomography, and contrast-enhanced ultrasound in evaluation of the ablated area. Radiol Med 121: 122-131.

51. Langan RC, Goldman DA, D'angelica MI, Dematteo RP, Allen PJ, et al. (2017) Recurrence patterns following irreversible electroporation for hepatic malignancies. J Surg Oncol 115: 704-710.

52. Kingham TP, Karkar AM, D'angelica MI, Allen PJ, Dematteo RP, et al. (2012) Ablation of perivascular hepatic malignant tumors with irreversible electroporation. J Am Coll Surg 215: 379-987.

53. Cheung W, Kavnoudias H, Roberts S, Szkandera B, Kemp W, et al. (2013) Irreversible electroporation for unresectable hepatocellular carcinoma: initial experience and review of safety and outcomes. Technol Cancer Res Treat 12: 233-241.

54. Niessen C, Jung EM, Wohlgemuth WA, Trabold B, Haimerl M, et al. (2013) Irreversible electroporation of a hepatocellular carcinoma lesion adjacent to a transjugular intrahepatic portosystemic shunt stent graft. Korean J Radiol 14: 797-800.

55. Cheng RG, Bhattacharya R, Yeh MM, Padia SA (2015) Irreversible Electroporation Can Effectively Ablate Hepatocellular Carcinoma to Complete Pathologic Necrosis. J Vasc Interv Radiol 26: 1184-1188.

56. Coelen RJS, Vogel JA, Vroomen L, Roos E, Busch ORC, et al. (2017) Ablation with irreversible electroporation in patients with advanced perihilar cholangiocarcinoma (ALPACA): a multicentre phase I/II feasibility study protocol. BMJ Open 7: e015810.

57. Herwald SE, Chen JH, Arellano RS (2016) Irreversible Electroporation for Treatment of Hepatocellular Carcinoma Adjacent to the Gallbladder. J Vasc Interv Radiol 27: 1093-1094.

58. Eller A, Schmid A, Schmidt J, May M, Brand M, et al. (2015) Local Control of Perivascular Malignant Liver Lesions Using Percutaneous Irreversible Electroporation: Initial Experiences. Cardiovasc Inter Rad 38: 152-159.

59. Martin RC, Schwartz E, Adams J, Farah I, Derhake BM, et al. (2015) Intra - operative Anesthesia Management in Patients Undergoing Surgical Irreversible Electroporation of the Pancreas, Liver, Kidney, and Retroperitoneal Tumors. Anesth Pain Med 5: e22786.

60. Kos B, Voigt P, Miklavcic D, Moche M (2015) Careful treatment planning enables safe ablation of liver tumors adjacent to major blood vessels by percutaneous irreversible electroporation (IRE). Radiol Oncol 49: 234-241. 
61. Dong $S$, Wang $H$, Zhao $Y$, Sun $Y$, Yao $C$, et al. (2018) First Human Trial of High-Frequency Irreversible Electroporation Therapy for Prostate Cancer. Technol Cancer Res Treat 17: 1533033818789692

62. Scheltema MJ, Chang JI, Van Den Bos W, Gielchinsky I, Nguyen TV, et al (2018) Impact on genitourinary function and quality of life following focal irreversible electroporation of different prostate segments. Diagn Interv Radiol 24: 268-275.

63. Murray KS, Ehdaie B, Musser J, Mashni J, Srimathveeravalli G, et al. (2016) Pilot Study to Assess Safety and Clinical Outcomes of Irreversible Electroporation for Partial Gland Ablation in Men with Prostate Cancer. J Urology 196: 883-889.

64. Van Den Bos W, Jurhill RR, De Bruin DM, Savci-Heijink CD, Postema AW, et al. (2016) Histopathological Outcomes after Irreversible Electroporation for Prostate Cancer: Results of an Ablate and Resect Study. J Urol 196: 552-559.

65. Wendler JJ, Ganzer R, Hadaschik B, Blana A, Henkel T, et al. (2017) Why we should not routinely apply irreversible electroporation as an alternative curative treatment modality for localized prostate cancer at this stage. World J Urol 35: 11-20.

66. Wendler JJ, Klink F, Seifert S, Fischbach F, Jandrig B, et al. (2016) Irreversible Electroporation of Prostate Cancer: Patient-Specific Pretreatment Simulation by Electric Field Measurement in a 3D Bioprinted Textured Prostate Cancer Model to Achieve Optimal Electroporation Parameters for Image-Guided Focal Ablation. Cardiovasc Inter Rad 39: 1668-1671.

67. Van Den Bos W, De Bruin DM, Jurhill RR, Savci-Heijink CD, Muller BG et al. (2016) The correlation between the electrode configuration and histopathology of irreversible electroporation ablations in prostate cancer patients. World J Urol 34: 657-664.

68. Scheltema MJ, Chang JI, Van Den Bos W, Gielchinsky I, Nguyen TV, et al. (2018) Impact on genitourinary function and quality of life following foca irreversible electroporation of different prostate segments. Diagn Interv Radiol 24: 268-275.

69. Van Den Bos W, Scheltema MJ, Siriwardana AR, Kalsbeek AMF, Thompson $\mathrm{JE}$, et al. (2018) Focal irreversible electroporation as primary treatment for localized prostate cancer. Bju Int 121: 716-724.

70. Scheltema MJ, Van Den Bos W, De Bruin DM, Wijkstra H, Laguna MP, et al. (2016) Focal vs extended ablation in localized prostate cancer with irreversible electroporation; a multi-center randomized controlled trial. BMC Cancer 16: 299.

71. Fitzal F, Mittlboeck M, Trischler H, Krois W, Nehrer G, et al. (2008) Breastconserving therapy for centrally located breast cancer. Ann Surg 247: $470-$ 476 .

72. Neal RE, Singh R, Hatcher HC, Kock ND, Torti SV, et al. (2010) Treatment of breast cancer through the application of irreversible electroporation using a novel minimally invasive single needle electrode. Breast Cancer Res Treat 123: 295-301.

73. Neal RE, Davalos RV (2009) The feasibility of irreversible electroporation for the treatment of breast cancer and other heterogeneous systems. Ann Biomed Eng 37: 2615-2625.

74. Goswami I, Coutermarsh-Ott S, Morrison RG, Allen IC, Davalos RV, et al (2017) Irreversible electroporation inhibits pro-cancer inflammatory signaling in triple negative breast cancer cells. Bioelectrochemistry 113: 4250.

75. Baur ADJ, Collettini F, Enders J, Maxeiner A, Schreiter V, et al. (2017) MRITRUS fusion for electrode positioning during irreversible electroporation for treatment of prostate cancer. Diagn Interv Radiol 23: 321-325.

76. Bhutiani $N$, Philips $P$, Scoggins $C R$, Mcmasters $K M$, Potts $M H$, et al. (2016) Evaluation of tolerability and efficacy of irreversible electroporation (IRE) in treatment of Child-Pugh B (7/8) hepatocellular carcinoma (HCC). HPB 18: $593-599$

77. Niessen C, Igl J, Pregler B, Beyer L, Noeva E, et al. (2015) Factors Associated with Short-Term Local Recurrence of Liver Cancer after Percutaneous Ablation Using Irreversible Electroporation: A Prospective Single-Center Study. J Vasc Interv Radiol 26: 694-702.

78. Golberg A, Bruinsma BG, Uygun BE, Yarmush ML (2015) Tissue heterogeneity in structure and conductivity contribute to cell survival during irreversible electroporation ablation by "electric field sinks". Sci Rep-Uk.

79. Au JT, Wong J, Mittra A, Carpenter S, Haddad D, et al. (2011) Irreversible electroporation is a surgical ablation technique that enhances gene transfer. Surgery 150: 474-479.
80. Yang Y, Qin Z, Du D, Wu Y, Qiu S, et al. (2018) Safety and Short-Term Efficacy of Irreversible Electroporation and Allogenic Natural Killer Cell Immunotherapy Combination in the Treatment of Patients with Unresectable Primary Liver Cancer. Cardiovasc Intervent Radiol 42: 48-59.

81. Sano MB, Fan RE, Cheng K, Saenz Y, Sonn GA, et al. (2018) Reduction of Muscle Contractions during Irreversible Electroporation Therapy Using High-Frequency Bursts of Alternating Polarity Pulses: A Laboratory Investigation in an Ex Vivo Swine Model. J Vasc Interv Radiol 29: 893-898. 